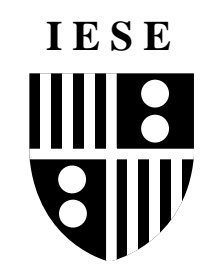

University of Navarra

\title{
DEREGULATION, INTEGRATION AND \\ MARKET STRUCTURE IN \\ EUROPEAN BANKING
}

\author{
Jordi Gual* \\ RESEARCH PAPER No 397 \\ October, 1999
}

* Professor of Economic Analysis for Management, IESE

Research Division

IESE

University of Navarra

Av. Pearson, 21

08034 Barcelona - Spain 


\title{
DEREGULATION, INTEGRATION AND MARKET STRUCTURE IN EUROPEAN BANKING
}

\begin{abstract}
(1)
This paper analyzes the impact of deregulation and market integration policies on the structure of European banking markets.

It argues that whether European integration will lead to large increases in EU-wide concentration will depend on the extent to which competition in banking is based on endogenous sunk costs or, alternatively, on variable costs and exogenous sunk costs.

The paper also highlights the role of own funds as a source of endogenous increasing returns. Finally, it proposes an empirical test of the dominant form of competition. This procedure is applied to data for eleven EU countries during the period 1981-1995.
\end{abstract}

(1) This is a revised version of the paper presented at the NBER/CEPR/Tokyo Centre for Economic Research Conference on "Competition policy, deregulation and re-regulation" held in Tokyo, 18-19 December 1998. Comments by T. Ito, T. Hoshi, X. Vives, J. Canals, C. Hurst and two anonymous referees are greatly appreciated. 


\section{DEREGULATION, INTEGRATION AND MARKET STRUCTURE IN EUROPEAN BANKING}

\section{Introduction}

The European banking industry has gone through a process of integration which reaches its peak with the adoption of the single currency in 1999. The completion of the single market for banking has involved the implementation of EU regulations aimed at opening domestic markets and partially harmonizing national banking systems. Most importantly, however, it has triggered in many countries the adoption of domestic deregulation programs that have drastically changed the competitive regime. This paper looks at the consequences of this joint process of deregulation and market integration on the structure of European banking markets.

Section 2 characterizes the completion of the integrated European banking market. The paper highlights the key deregulation and market opening policies and constructs country-level indicators that capture the different pace and extent to which EU member states have opened their borders, deregulated the domestic market and adopted the harmonized regulatory regime.

Whether EU member state banking markets become a single EU-wide market will depend on the importance of entry barriers set up by incumbents and on the presence of unexploited scale and scope economies in the industry. These issues are discussed in Section 3 . The paper argues that if entry barriers are not too high, the characteristics in terms of seller concentration of the resulting equilibrium with market integration will depend on the nature of competition in banking. Following Sutton (1991) and Schmalensee (1992), I argue that European banking markets will remain moderately concentrated if banks engage in competition through standard strategic variables such as price or customer service. Concentration is likely to increase (at the national and EU level) substantially, however, if competition focuses on endogenous sunk costs, which in banking may refer to the development of a brand image, the investment in electronic banking or the development of a strong capital base.

Section 4 provides an aggregate empirical analysis at the European level aimed at characterising the nature of banking competition during the period 1981-95. The parameter estimates show that banking competition in Europe can be characterized as focusing mostly on variable costs. If this type of competition continues to predominate in the future, we would expect a process of national concentration without generating in the medium term a significant increase in EU wide concentration.

A concluding section summarizes the main results of the paper. 


\section{Regulatory change in European banking}

Regulatory interventions in banking have been pervasive for many years and adopt many forms. This section assesses regulatory changes in European banking markets from the point of view of their impact on the competitive conditions in EU member state markets and the extent of market integration.

We will, thus, distinguish three types of regulations (1) (see Table 1), depending on their effect on domestic competition, the potential for exploitation of scale and scope economies and the external competitive position of banks.

Table 1. Regulatory intervention in banking

Regulations that soften domestic competition

Controls on interest rates and fees

Credit controls

Restrictions on entry

Restrictions on mergers and acquisitions

Controls on capital flows

Regulations that limit the scope and scale of banks

Domestic branching restrictions

Restrictions on establishment in foreign markets

Limits to activities within conventional banking

Limits to activities in insurance

Limits to activities in securities

Regulations that alter the external competitive position of banks

Reserve and investment coefficients

Solvency regulations

Capital adequacy requirements

Deposit insurance schemes

Restrictions on ownership linkages with non-financial firms

European banking has undergone a profound process of deregulation, with changes in the three categories of regulatory interventions. Only part of this process has been driven directly by EU legislation. Let us consider the three types of regulations in turn.

\section{Regulations that soften domestic competition}

Consider, first, the regulations that stifle the development of a domestic competitive environment and tend to support regimes of (implicit) collusion. This has been traditionally the consequence of restrictions on the entry of new domestic firms, or limitations to the free

(1) Obviously the impact of one specific regulatory intervention will in general depend on whether other regulatory measures are in place. Moreover, some regulations will fall under one heading, but have an indirect effect on other dimensions. 
deployment of competitive tools by firms (measures such as interest rate and fee controls) (1). Further dampening of competitive rivalry results from controls of capital flows that limit competition from foreign suppliers, particularly in wholesale markets where crossborder activities are easiest.

Table 2. Elimination of restrictions on domestic competition

Member State

Austria

Belgium

Denmark

Finland

France

Germany

Greece

Ireland

Italy

Luxembourg

Netherlands

Portugal

Spain

Sweden

United Kingdom

\section{Interest rate deregulation}

$1989 *$

1990

1988

$1985^{*}$

1990

1981

1993

1993

1990

1990

1981

1992

1992

$1985^{*}$

1979

\section{Liberalization of capital flows*}

1989-91*

1991

1982

$1991^{*}$

1990

1967

1994

1985

1990

1990

1980

1992

1992

$1992 *$

1979

Source: European Commission. The Single Market Review. Reports on the banking and credit sector and capital market liberalization.

* Data for Austria, Finland and Sweden have been collected specifically for this project. Capital flows controls for these countries refer to restrictions on investments and loans with foreign institutions. For the rest, the date corresponds to the full liberalization.

In many member states the changes in the competitive environment have been the result of a domestic policy of a gradual lifting of restrictions on interest rates, credit controls and (in some cases) entry of new banks. In some countries the elimination of these restrictions can be understood, however, as a pre-emptive move in the wake of EU integration policy. Table 2 provides a summary of the key liberalization dates (2) and shows that there are significant differences across countries.

(1) The competitive impact of deposit rate controls has been analyzed in models of banking competition. These models have focused on the effect on loan rates, but quite often deposit rate controls have been implemented together with interventions in the credit market (i.e. investment coefficients). More interestingly, economic analysis shows that the introduction of restrictions on prices shifts competition to customer service (i.e. branching, to the extent that an increased network improves customer access).

(2) In fact, some of these dates underestimate the pace of liberalization since they correspond to the liberalization of all rates and many countries started the liberalization process earlier (i.e. France liberalized fees in 1986, Spain and Portugal started the liberalization of interest rates in the late eighties). Table 2 does not include credit controls since those were used only in some of the countries (the UK lifted restrictions in 1980, France in 1986 and Sweden in 1985. Spain introduced restrictions temporarily around 1990). 
Table 2 also shows the dates of liberalization of capital flows, and therefore reflects the potential for development of cross-border banking. Note that the adoption of the EU banking directives (the first banking directive and the second banking directive, see below) which allow or reduce the cost of the operation of branches in other EU member states has also had a significant impact on the domestic competitive conditions.

\section{Regulations that prevent the exploitation of scale and scope economies}

A second set of regulations comprises limits to the range of activities that can be undertaken by banking firms. These constraints prevent the exploitation of economies of scale and scope which may be important in the financial industry. Some regulations impose restrictions on the lines of business of banks (i.e. restricting activity in insurance and securities), and may even impose restrictions within conventional commercial banking (i.e. in terms of the maturity of loans and/or deposits) (1). Sometimes there are limitations to branching. This is particularly the case with regard to establishment in foreign countries. In such an instance, of course, the regulatory intervention affects not only the possibility of exploiting increasing returns, but also contributes to the maintenance of cosy competitive conditions.

This is a key area where EU directives have had a major impact. In particular, the first banking directive (FBD) and specially the second banking directive (SBD), with their provisions for mutual recognition, home country supervision and the elimination of capital requirements for branches within other EU member states, have allowed the exploitation of scale economies related to branching in foreign markets with the associated advantages in terms of risk diversification.

Note that other regulatory interventions that may restrict firm growth have been less affected by EU laws. In particular, member states have decided unilaterally to lift restrictions on branching of all or some institutions (i.e. Portugal in 1984, France in 1987, Spain in 1988 and Italy in 1990). Similarly, even if the second banking directive sets a list of activities which are covered by the single passport, there is still some scope for differences across countries in terms of the kind of activities that may be pursued by banks in non-bank financial markets such as insurance and securities.

European (continental) banking has usually been characterized by a universal banking approach. By granting a single passport, the SBD provides an incentive (and a focal point) for harmonization. However, the SBD does not include insurance activities. Overall, differences across countries persist (see Table 3). However, they do not appear to be of practical significance compared with the differences relative to other OECD countries (such as the US and Japan) and they are unlikely to constitute a source of competitive advantage for banks facing a less restrictive regime.

\section{Regulations that alter the external competitive position of banks}

The third category of regulatory intervention includes several measures that influence the cost of funds and, as a consequence, the external competitive position of domestic banks. Prudential regulations such as solvency and own funds requirements, limits

(1) By and large, member states that had important specialized institutions have reduced the segmentation of the domestic industry (i.e. France in 1984, Italy in 1993, the UK in 1985, Spain in 1991, Sweden in 1987). 
Many EU regulations have been devoted to harmonising prudential requirements. The objective has been to create a level playing field by imposing minimum standards on regulations which, on the grounds of solvency and stability, impose costs on domestic banks. The EU directives include legislation on solvency ratios, the definition of own funds, large exposures and others. Table 4 summarizes the pace of adoption of this legislation by EU member states. The EU standards constitute only a lower bound on prudential requirements and several countries have adopted legislation which is even more stringent.

As for reserve and investment coefficients, many of the countries with significant interventions dismantled them in the late eighties and early nineties (France in 1987, Portugal in 1994, Spain gradually up to 1992). Nevertheless, some differences remained across countries with regard to the reserve coefficient, so that countries such as Belgium, the Netherlands and the UK, where the coefficient was almost nil, coexisted in the EU with others where by 1995 the level was still comparatively high (i.e. Germany and, in particular, Italy).

Altogether, the information summarized in Tables 2 to 4 will be used later on to construct a summary index of deregulation for each member state for the period 1981- 1995 .

Table 4. Harmonisation of prudential regulation in Europe

\begin{tabular}{|cc|}
\hline Member State & Period of implementation (1) \\
& \\
Austria & $93-95$ \\
Belgium & $90-94$ \\
Denmark & $89-95$ \\
Finland & $90-95$ \\
France & $90-95$ \\
Germany & $90-92$ \\
Greece & $92-95$ \\
Ireland & na \\
Italy & $91-93$ \\
Luxembourg & $92-93$ \\
Netherlands & $91-95$ \\
Portugal & $90-95$ \\
Spain & $85-93$ \\
Sweden & $89-95$ \\
United Kingdom & $85-95$ \\
& \\
Source: European Commission. The Single Market Review. Reports on the banking and \\
credit sector. \\
(1) The following directives have been included: 86/635 Consolidated Accounts; \\
89/117 Accounting documents of branches of foreign credit institutions; 89/299 \\
Own funds and modifications (91/633); Solvency ratio (89/647); and the Deposit \\
insurance directive (94/19). \\
\end{tabular}




\section{The integration of banking markets}

The literature on market integration (1) shows that in conditions of imperfect competition there is a wide range of factors which determine the degree of integration of previously segmented markets and the structure of the resulting market.

First of all, the size of transport/transaction costs or the importance of consumer preferences for local suppliers may segment markets naturally. Secondly, there may be significant economic or legal barriers that prevent entry into new markets. Finally, there is the extent of the economies of scale (and scope) which can be obtained by serving the whole integrated economic area.

These points, and particularly economies of scale, are looked at below for the case of the banking industry. The first step in the examination is to list the distinctive elements which characterise banking activities.

The banking system basically has three functions (2):

1) To reduce transaction costs in payment systems by eliminating the need for costly verification of the solvency of the parties involved in a transaction. This heading of transaction cost reduction also covers the task of redenominating assets, which banks perform by accommodating the desires of their deposit and loan holders as regards net positions in financial assets. Normally banks provide deposit holders with assets in lower denominations than those generated in their loan and investment activities, reducing the indivisibility generated in the investment process.

2) Term transformation of assets by granting long-term credits (non liquid assets) and generating deposits which generally have more liquidity. In this activity banks incur two risks: liquidity risk (since part of their deposit liabilities are payable in the short term and their assets are not realisable in the same term), and interest rate risk, insofar as fluctuations in interest rates can alter the market value of assets and liabilities.

3) Transformation of the quality of assets. By delegation from their customers banks manage credit risk by processing information and supervising their portfolio of loans. These activities, together with the diversification obtained by sharing risks, enable banks to issue securities of their own whose profitability and risk differ from those of the assets on their balance sheet, and which are potentially attractive to deposit holders and other potential purchasers of bank debt.

(1) See Baldwin \& Venables (1995).

(2) Dewatripont \& Tirole (1994, pp. 104-112) distinguish four functions: the reduction of transaction costs through term transformation, the reduction of transaction costs in payment systems, delegated supervision and the provision of liquidity. Freixas \& Rochet (1997, pp. 2-7) list the following: payment services, asset transformation (including adjustment of denominations and transformation of quality \& maturity), risk management and the processing of information and supervision. Finally, Vives (1991, p. 11) lists the reduction of costs in financial transactions, portfolio management, the transformation of non liquid assets into liquid liabilities by providing liquidity insurance and the diversification of risk to economic agents, and the minimising of transaction costs incurred in supervising credit (see also the classification presented by Battarchaya \& Thakor (1993)). 
How far and in what way does the nature of banking as summed up in these three functions condition the impact of a market integration process? Let us look first at the factors which can keep markets segmented.

\subsection{Differentiation and barriers to entry in banking}

The establishing of a legally integrated European banking market as a result of the introduction of the euro does not necessarily mean in practice that a single market is created.

First of all, in spite of advances in financial service provision with no need for physical proximity, there are still high "transport costs" in retail banking and this means that entry into foreign markets must be based largely on the opening (or acquisition) of a branch network.

Furthermore, even though horizontal differentiation is hard to achieve in banking (financial products are easily imitated), this is not incompatible with preferences for domestic service providers, based on perceived quality (see below). These preferences may lead to foreign competitors having only a very small share of local markets.

In fact it is difficult empirically to distinguish between this possibility and the impact of economic barriers to entry. These barriers are sometimes inherent to the deployment of banking activities, but may also be the outcome of strategic behaviour (1).

One of the key features of banking that favours incumbents is the advantage in terms of information enjoyed by local banks. Dell'Ariccia (1998) shows that informational asymmetry hinders the entry of banks into new markets even when legal restrictions on entry are lifted. In more informal terms, knowledge of the local market and information held by banks about their customers (e.g. information on transaction deposits at the time of granting loans) can give significant advantages.

A second source of incumbent advantage and a potential entry barrier is the widespread network of branch offices owned by the leading domestic banks. Although these networks are not, strictly speaking, an irrevocable commitment to market presence, they do provide a formidable position of established capacity on the market, and may deter entry.

A third factor favouring local banks, especially the largest of them, is reputation associated with size. In banking, perceived quality is often associated with perceived safety and low risk levels, and this may come from size insofar as size permits a diversification in loan investment and can even lead to expectations of intervention by regulatory bodies in any hypothetical insolvency.

A fourth factor is switching costs. Banking usually involves a long-lasting contractual relationship in which, from the customer's viewpoint, any change involves considerable cost: deposit holders attempt to make their current financial decisions compatible with their investments in contractual relationships established in the past (2).

(1) See Vives (1991) and Gual \& Neven (1993).

(2) Klemperer (1992). 
Finally, it is well known that there can be political obstacles to the entry of foreign banks via take-overs, given the role played by banks in payment systems and the financial system in general (1).

\subsection{Economies of scale in banking}

There is a long tradition of analysis of the importance of economies of scale in banking. In the face of an effective enlargement of the market to European scale, it is crucial to assess the importance of these economies relative to the size of domestic markets and the EU market as a whole. If we assume that integration is effective and strategic barriers do not prevent entry, we then have to ask whether the size of national banks is optimal for the new European environment.

This analysis can be carried out by looking at the three basic functions of banks.

In the area of transaction cost reduction there will be economies of scale if there are increasing returns to banking operations, be it in asset or liability management. Here we must of course include ATMs, branch offices, back-office software, Internet software, and the like. If transactions technology incorporates these elements and not purely variable inputs such as personnel, we shall find increasing returns.

Until recently, empirical evidence concerning the scale of the economies associated with these factors did not favour the hypothesis of increasing returns (2). For instance, in a review of the relevant literature in 1993 Berger and others concluded that unexploited economies of scale might account for $5 \%$ of differences in costs, while $20 \%$ were accounted for by X-inefficiency. reasons (3).

However, more recent studies during the nineties have changed this view, for various

First of all, the method used predominantly in the 1980s (the econometric estimation of trans-logarithmic cost functions) has been criticised for being an approach which cannot be applied reliably to samples of banks with very different sizes and product portfolios (4). Secondly, these studies use more recent data from 1990-95, in which the impact of new technologies (and of the extension of the market in the USA) is probably more easily detectable. Finally, savings in costs associated with risk have been incorporated into the analyses of economies of scale. In view of the functions carried out by banks, it would seem essential to include this area in the analysis.

In relation to the function of banks as providers of liquidity to their customers, size entails a reduction in costs insofar as it permits a diversification of the customer base, and therefore reduces the likelihood of a liquidity shortage. Hughes, Lang, Mester \& Moon (1996) develop a model in which geographical expansion enables banks to increase their

(1) ERE (1996) mention the "general good" clause as a potential source of legal constraints within the EU to entry by institutions from other EU member states.

(2) See Vives, (1991) and, more recently, De Bandt (1997) and Davis \& Salo (1997).

(3) The same cannot be said of economies of scope, whose empirical relevance is called into question (Berger et al., 1993).

(4) McAllister \& McManus, (1993). 
diversification and thus reduce the cost of covering liquidity risks. Naturally, if the bank is not risk neutral, expansion does not necessarily entail any reduction in unit costs, as some banks may use the opportunity to increase other risks. Krasa \& Villamil (1992) argue that reductions in risk will be offset by increases in supervision costs. However, economies of scale might also arise in relation to the function of banks as credit risk managers.

Indeed, the very existence of financial intermediaries is in fact based on economies in the process of information and supervision (1). However, economies of scale in supervision are likely to be soon exhausted, and true savings are generated by the impact of size on the risk (be it real or perceived) of loan portfolios.

First of all, size can in itself entail a reduction in the cost of obtaining resources (deposits or borrowing) if there is a reputation ("too big to fail") effect. Clearly, the largest banks may be seen by customers as safer and may thus benefit from a lower cost of external resources. Boot \& Greenbaum (1993) develop a model in which they show that the existence of deposit insurance eliminates incentives to create low risk reputation and thus entails a more aggressive risk position, and with it an increase in size. Note, however, that a larger size can also entail a diversification in assets, which reduces aggregate risk and thus also permits a reduction in the (unit) cost of resources.

At an empirical level, there is evidence in the study by McAllister and McManus (1993) of economies of scale associated in part with the incorporation of risk into the analysis. These authors find that small banks in the USA (2) (those with less than 500 million dollars in assets, and especially those with less than 100 million dollars) face cost disadvantages of approximately $10 \%$ (3). However, in their investigation the cost function is still U-shaped with a large flat section between 500 million and 10,000 million dollars. The banks included in the sample have total assets up to 10,000 million dollars.

As indicated, however, empirical investigations in this field have changed over time, with growing evidence being found of economies of scale. For example, Berger and Mester (1997) use a Fourier function and, controlling for X-inefficiency, find that the disadvantages arising from small size cause cost differences of $20 \%$, a figure similar to that estimated in the studies of X-inefficiency. This figure was found in spite of the fact that these authors did not examine the largest banks (those with over 10,000 million dollars in total assets). These authors include the role of equity and how it impacts on the scale of banking activities.

Hughes \& Mester (1998) explicitly take into account that own funds constitute a source of risk reduction (4) and model a cost function considering not only the impact of equity on the cost of external resources but also the choice of the level of equity by the bank in a model where the bank takes into account both the expected level of profits and risk. These authors analyse a sample of large banks (with assets of more than 1,000 million dollars for 1990 and 1991) and find economies of scale associated with the level of capitalisation of banks which are statistically significant and quantitatively large.

(1) See, for example, Freixas \& Rochet, op. cit., page 29.

(2) Much of the evidence available is for the USA. There are far fewer studies for Europe, and those which have been made provide, to date, results along the lines of the traditional US literature (see De Bandt, 1997).

(3) Earlier studies put minimum efficient size at just 100 million dollars (Berger, 1993).

(4) Recently, though this is not an estimation of cost functions, Demirgüç-Kunt and Huizinga (1998) analyse a sample of eighty countries for the period 1988-95, and find that well capitalised banks obtain higher financial margins and higher profitability. They believe this to be consistent with a scenario in which banks with better solvency ratios have lower financing costs due to the perception of a lower risk of bankruptcy. 


\subsection{How do Banks Compete?}

The consequences of European integration for the structure of banking markets within member states and at the EU level will be determined by the characteristics of the economies of scale in the industry and by the nature of bank customers' preferences.

First of all, let us consider a situation in which banks compete on prices or unit costs. This would make banking an activity in which firms compete for market share by means of a variable expense, closely linked to their level of intermediation. This alternative covers both competition through higher interest rates on deposits (or lower interest rates on loans) as well as strategies based on improving customer service. In this last case, market share is increased by committing more resources (for example, more qualified personnel) per customer or per unit of assets or liabilities intermediated.

It must also be observed that competition through services which improve access to the bank by clients (e.g. branch offices and ATMs) is a similar strategy, in that the fixed costs associated with a branch office (or a cash dispenser) are quickly exhausted in relation to market size. The number of branches and cash dispensers (and their cost) grows along with the level of intermediation of the bank. From an equivalent viewpoint, this is a type of expenditure which ceases to be effective in gaining market share at comparatively low levels (having two branches close to home rather than one is unlikely to modify the customer's willingness to pay).

Consider next, an alternative view of banking, even though it is not necessarily incompatible with the previous one. Suppose banking involves activities in which capturing market share (or increasing the willingness of consumers to pay) is achieved by committing (non recoverable or sunk) expenses which are fixed, that is, unrelated to the volume of operations or intermediation of the bank.

There are many examples of potentially relevant fixed expenses of this type: the development of a commercial brand or image, software for Internet banking or back-office operations, etc. In these cases the expense involved does not depend on the number of customers or the volume of operations of the bank (1), but it affects the company's ability to compete. Using the terminology of Sutton (1991), these are endogenous sunk (fixed) costs. These must be distinguished from conventional fixed costs (which Sutton refers to as exogenous), which generate economies of scale but do not affect the bank's ability to increase its market share.

In fact, equity increases which allow banks to expand their size can also be considered as a source of endogenous increasing returns. They affect market share via the reputation perceived by customers. Even if it is not a fixed cost, it involves decreasing marginal costs due to the risk effect discussed above.

The simple bank competition model developed below examines more formally the implications of the nature of competition on the equilibrium structure of the market in a model with free entry. As in Sutton (1991) and Schmalensee (1992), the results show that the impact of market growth on structure (summed up by an index of firm concentration)

(1) In the case of Internet services and back-office operations software development is independent of the volume of operations of the bank, but of course this is not necessarily so for other associated costs such as expenditure on telecommunications equipment. 
depends crucially on how companies compete. If competition is based on variable costs, the market tends to fragment as its size increases. At the opposite extreme, if rivalry is centred on endogenous sunk costs there is a downward limit and concentration is not necessarily reduced when the market grows (1).

The implications of this result for the structure of the future European banking market are clear: if the fixed cost competition model dominates there will be a strong trend towards pan-European concentration in the coming years. If, however, the variable cost model is more relevant the increases in concentration (which have already taken place in part) will be less significant and may reflect the adjustment, at the member State level, to a higher level of domestic rivalry.

\subsection{A model of banking competition}

The model which I use is a variant of the Klein-Monti (2) model with bankruptcy risk developed by Dermine (1986).

We assume that banks finance an asset whose value is a random variable $a$ with a density function $f(a)$ and a distribution function $F(a)$ defined in the interval $(k, K)$.

The bank $i$ maximises expected profits $\Pi$ according to the following expression (for the sake of simplicity the subscript $i$ is omitted for the moment):

$$
\Pi=\int_{p l}^{K}\left[(p l(p)+g b-q d(q, e)] f(a) \delta a+\int_{a^{*}}^{p l}[a+g b-q d(q, e)] f(a) \delta a-r e\right.
$$

subject to the restriction $b+l=d+e$

where $l(p)$ is the loan demand function and $p$ its interest rate, $g$ the interest rate on loans in the public debt market (denoted by $b$ ), $r$ the return on own funds $e$, and $d(q, e)$ the deposit supply function, which depends on the vectors of interest rates $q$ and on the equity of the various banks $e$. The first integral represents profits when the borrower can repay his debt, and the second integral profits in case of borrower's bankruptcy. The equity variable is a proxy for solvency in a context of limited coverage of deposit insurance (3). We assume therefore product differentiation on the liabilities side of the market. $a^{*}$ is equal to $(q d-g b)$ and indicates the asset value below which the bank is insolvent.

By a simple transformation this expression can be written as:

$$
\operatorname{Max}_{p, q, e}[(p-g) l(p)+(g-q)(q, e) *(g-r) e]-\int_{a^{*}}^{p l} F(a) \delta a
$$

(1) An explicit application of a model of endogenous sunk costs with two stages to banking can be found in Cerasi et al. (1998).

(2) The Klein-Monti model is subject to several criticisms. See, for example, Freixas and Rochet (1997, chapter 3). Nevertheless, it is a useful simple framework that captures some of the key implications of imperfect competition in banking. A key assumption is the separability between the markets for loans and deposits, which hinges upon the existence of an interbank market, the non-existence of contracts which tie loans to deposits and the separability of the cost function between assets and liabilities.

(3) Note that we include $e$ and not the more conventional capital to assets ratio because the level of capital $e$ captures better the effect of "too large to fail" expectations on consumer preferences. 
The first order conditions in a bank oligopoly model in which $N$ symmetrical banks compete in loans, deposits and equity levels are as follows (1):

$$
\begin{aligned}
& (p-g)(\partial l / \partial p)+l(p)-F(p l)(p(\partial l / \partial p)+l(p))=0 \\
& (g-q)(\partial l / \partial p)-d(q, e)=0 \\
& (g-q)(\partial d / \partial e)+g-r=0
\end{aligned}
$$

As in Dermine (1986), interest rates for deposits and loans are determined independently. In Dermine's model the inclusion of bankruptcy risk when there is no deposit insurance does not modify the setting of the deposit rate in the Klein-Monti model, and leaves the optimum level of equity undetermined. This is because it is assumed that deposit holders know the function $f(a)$. In our case introducing bankruptcy risk is relevant even in the absence of deposit insurance, as the supply of deposits depends on the solvency of banks, and therefore on equity.

We then assume a specific deposit supply function according to which the market share of a bank $i$ can be written as follows:

$$
\frac{d_{i}}{\sum_{j=l}^{N} d_{j}}=\frac{u_{i}^{\varepsilon}}{\sum_{j=l}^{N} u_{j}^{\varepsilon}}
$$

where

$\varepsilon>0$

and $u$ is a utility measure.

This market share function can be interpreted as the result of a random utility model (see Schmalensee, 1992). The parameter $\varepsilon$ captures the sensitivity of market share to changes in $u$.

We then assume that the utility $u$ derived by customers from operating with bank $i$ has two components: price $q$ and the level of equity $e$. Using a Cobb-Douglas function with parameter $\alpha(0 \leq \alpha \leq 1)$ to add both factors we obtain the following expression for the market share.

(1) Since this is a standard model we will not be concerned with technical issues such as the existence of equilibrium or the analysis of second order conditions. We focus on deposit-taking competition. Due to the existence of an interbank market, loan market competition is not very interesting since the level of own funds does not affect loan demand. Modelling two-sided competition becomes more complex if the existence of an interbank market is assumed away (see Freixas and Rochet, op. cit., page 65). 


$$
d_{i}=D \frac{q_{i}^{\varepsilon-\alpha \varepsilon} e_{i}^{\alpha \varepsilon}}{\sum_{j=1}^{N}\left(q_{j}^{\varepsilon-\alpha \varepsilon} e_{j}^{\alpha \varepsilon}\right)}
$$

where $D$ is the size of the deposit market.

This enables us to express the first order conditions for $q$ and $e$ as follows:

$$
\begin{aligned}
& \frac{g-q}{q}=\frac{1}{(\varepsilon-\alpha \varepsilon)} \frac{N}{(N-1)} \\
& e=\frac{(g-q)}{(r-g)} \alpha \varepsilon D\left[\frac{1}{N}=\frac{1}{N^{2}}\right]
\end{aligned}
$$

Adding an exogenous fixed cost $\sigma$ and imposing a zero profit condition we obtain the following expression for the equilibrium number of companies $N^{*}$ :

$$
\frac{g D}{\sigma}=\frac{(\varepsilon-\varepsilon \alpha)(N *-1)+N *}{1-\alpha \varepsilon\left(1-\frac{1}{N *}\right)}
$$

Assuming that the elasticity $\varepsilon$ equals 1 , we can obtain in an explicit form the formal relationship between the number of banks in equilibrium (the degree of concentration) and the size of the market for the two extreme cases $\alpha=1$ and $\alpha=0 . \alpha=1$ shows a situation of competition on fixed costs and $\alpha=0$ one of competition on variable costs.

\section{Competition on variable costs}

For $\alpha=0$ we obtain:

$$
N *=\frac{1+(g D / \sigma)}{2}
$$

The number of banks grows with the market and concentration (the inverse of the number of symmetrical banks in equilibrium is the Herfindhal's index) tends to zero as the market expands.

$$
\frac{1}{N *}=\frac{2}{1+\left(\frac{g D}{\sigma}\right)}
$$


If we relax the restriction that the elasticity is one (thus allowing for the possibility of different degrees of competition as captured by $\varepsilon$ ), the expression for the number of banks in equilibrium becomes:

$$
N *=\frac{\varepsilon+(g D / \sigma)}{1+\varepsilon}
$$

The linear relationship between market size and the number of banks in free-entry equilibrium is maintained. As before, concentration declines with market size given any level of competition.

$$
\frac{\partial(1 / N *)}{\partial\left(\frac{g D}{\sigma}\right)}<0
$$

If we fix the size of the market $(g D / \sigma)$, greater competition on prices (larger $\varepsilon$ ) leads to less companies entering the market and therefore to a greater degree of concentration (1):

$$
\frac{\partial(1 / N *)}{\partial \varepsilon}>0
$$

Finally, for most market sizes concentration drops faster as the market expands if there is more competition (2). Conversely, the larger the market, the smaller the increase in concentration produced by greater competition. In terms of the cross-partial derivatives these results imply:

$$
\frac{\partial^{2}(1 / N *)}{\partial\left(\frac{g D}{\sigma}\right) \partial \varepsilon}<0
$$

\section{Competition on fixed costs}

For $\alpha=1$, and assuming again that $\varepsilon=1$, we obtain:

$$
\frac{1}{N^{*}}=\left(\frac{g D}{\sigma}\right)^{-1 / 2}
$$

(1) These results resemble, of course, those obtained by Schmalensee (1992), as one-stage equivalents of the two-stage game results developed by Sutton (1991).

(2) It is easy to demonstrate that both results require $\varepsilon+2>(\mathrm{gD} / \sigma)$. Only if the level of competition is very low in relation to market size, that is if $\varepsilon+2<(\mathrm{gD} / \sigma)$, do we obtain the opposite effect. See Appendix 1 for details. 
This means that concentration drops as the market expands, but it does so at a lower rate than in the variable costs model.

The expression for the number of banks in equilibrium when $\varepsilon \neq 1$ is given by (1):

$$
\frac{1}{N^{*}}(1-\varepsilon)+\left(\frac{1}{N^{*}}\right)^{2} \varepsilon-\frac{1}{g D / \sigma}=0
$$

This implies that concentration is again negatively correlated with market size and positively correlated with the level of competition, measured by $\varepsilon$. Note, moreover, that concentration tends to $\mathrm{N}^{* *}$ (where $\mathrm{N}^{* *}=\varepsilon /(\varepsilon-1)$ ) when the market tends to infinity.

The effect of market expansion on concentration will also depend on the level of competition. If $\varepsilon<1$, the fixed costs model leads to results similar to the variable costs model, since concentration tends towards zero as the market expands (a negative cross-partial derivative).

However, for $\varepsilon>1$ the behaviour of concentration is radically different. Then, for higher levels of competition the effect of market expansion on concentration declines. Conversely, the larger the market, the stronger the pro-concentration effect of an increase in competition (the cross-partial derivative is positive, see Appendix 1 for details).

In summary, the analysis of the two cases (variable and fixed costs) reveals that the direct effects of market size and competition on the level of concentration are the same whatever the nature of competition. If market size increases, concentration goes down. If the level of competition is higher, concentration goes up.

The results also show that, for the most relevant parameter values, the key difference between the two cases is how the effect of market size on the level of concentration changes with higher levels of competition. With variable costs, increases in competition reinforce the negative relationship between concentration and market size, whilst the opposite happens with fixed cost competition. This difference between the two cases will be the basis of the empirical test which is described next.

\section{Empirical analysis}

The theoretical model establishes some aggregate equilibrium relationships between market variables which can be tested with market data. This analysis concentrates on the relationship between concentration, competition and market size.

The following specification provides a simple setup which nests the two alternative models under examination:

$$
\ln \mathrm{CO}_{\mathrm{it}}=\beta_{0}+\beta_{1} \ln \mathrm{S}_{\mathrm{it}}+\beta_{2} \mathrm{C}_{\mathrm{it}}+\beta_{3} \mathrm{C}_{\mathrm{it}} \ln \mathrm{S}_{\mathrm{it}}+\mathrm{v}_{\mathrm{it}}
$$

(1) See Schmalensee (1992). 
where $\mathrm{CO}$ is a concentration variable, $\mathrm{S}$ is a market size variable, $\mathrm{C}$ is a competition variable and $\mathrm{v}$ is an error term. The subscripts $i$ and $t$ refer to countries and years for which observations are available.

If banking competition takes place fundamentally on variable costs, the concentration index should be correlated negatively with market size and positively with the level of competition in a sample of countries with time series data. In terms of coefficients this means that $\beta_{1}<0$ and $\beta_{2}>0$. Furthermore, as derived from the theoretical model, the level of competition would be expected to affect the impact of market expansion on concentration. In general, the higher the level of competition, the greater the effect of an increase in market size on the decline in concentration. In terms of parameters this means that $\beta_{3}<0$. This parameter restriction is, of course, also valid for changes in the level of competition, so that increases in concentration entailed by greater competition are less important in larger markets.

If competition is based on fixed costs, an increase in competition entails, as before, an increase in concentration: $\beta_{2}>0$. The relationship between concentration and market size is also negative $\beta_{1}<0$. However, unlike the case of competition on variable costs, the combined impact of both variables is positive in this case: $\beta_{3}>0$. For instance, the greater the level of competition, the smaller the negative effect of an increase in market size on concentration.

\subsection{The data}

The data on concentration and market size for 1985, 90 and 95 is summarized in Chart 1 for fourteen countries in the EU. Due to insufficient information on deregulation changes, the empirical analysis was performed for eleven European Union countries with data from 1981 to 1995.

Chart 1. Concentration and market size in European banking (1985-95)

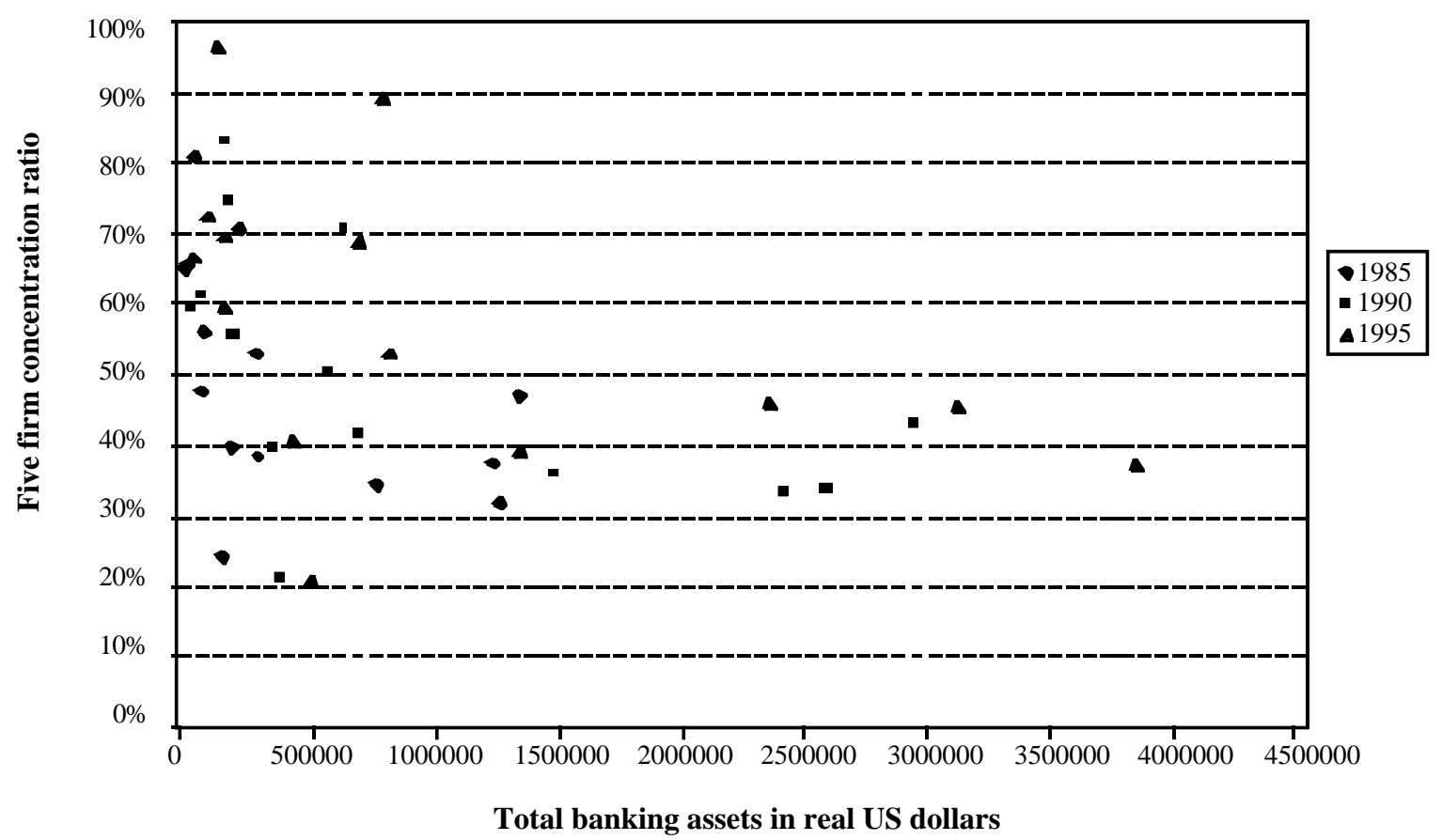


The concentration variable is based on a standard concentration ratio (C5) constructed as the percentage of assets at year end corresponding to the top five banks in each banking system. $\operatorname{lnCO}$ is the logit transformation of $\mathrm{C} 5$ so that it does not take values between 0 and 1 . Thus:

$$
\ln C O=\ln \frac{C 5}{(1-C 5)}
$$

Market size is measured by the total assets of the banking industry in constant dollars (1). Two observations must be made at this point.

First of all, as derived from the model, the relevant variable is market size in relation to the fixed exogenous establishment costs $\sigma$. We shall assume that these are the same for all markets and do not change over time.

Secondly, the theoretical model shows that market size depends on the level of interest rates (in the model, the inter-bank debt or public debt rate $g$ which segments the loan and deposits markets). Therefore, we shall use two alternative variables to measure market size. The first is total assets and the second is assets times the interest rate, which is a revenues measure.

Finally, the competition variable $\mathrm{C}$ is proxied with a variable which shows the degree of deregulation of the industry. This variable is constructed with the information summarized in section 2 on the adoption of liberalisation measures by European countries between 1981 and 1995 (2). Two alternative variables are considered: the first is a variable of annual indicators of the adoption of liberalisation measures (CA) and the second is constructed by the cumulative annual indicators (CC). This second variable has a value between 0 and 9 for those countries which implement all the liberalisation measures considered within the period under analysis.

Finally, the analysis will allow the intersection term to differ from one country to another, introducing a fixed effect. This will capture differences in concentration levels between countries which are not explained by the right-hand side variables.

(1) The data on total assets come from the Bank Profitability database of the OECD. Data on the leading banks were collected from The Banker.

(2) See Tables 2 to 4 . For the econometric analysis we have considered nine deregulation indicators, each of them including different deregulation measures or directives. Before the adoption of the deregulation measure the indicator takes a value of 0 and a value of 1 in the period in which the measure is adopted. Whenever a directive has been adopted over several years, the unit value of the indicator is spread proportionally over the relevant period. For example, a country which adopts all deregulation measures in, say, 1993 will have a deregulation variable of 0 between 1980 and 1992, of 9 for 1993 and of 0 thereafter. The cumulative deregulation variable will, however, be 0 up to 1992 and 9 afterwards. The nine indicators are: 1) interest rate deregulation; 2) freedom of establishment; 3) the implementation of the First Banking Directive; 4) the implementation of the Second Banking Directive; 5) the liberalization of capital flows; 6) the adoption of the directive on branch establishment and head offices outside the EU; 7) the adoption of the directives on consolidated surveillance; 8) the adoption of the deposit insurance and money laundering directives; and 9) the adoption of the directives on prudential regulation. Whenever the indicator is composed of several directives (as in 7,8 and 9) all the directives included are given the same weight. Indicator 7 includes directives 83/350, 92/30 and 86/365. Indicator 9 includes directives 89/299, 91/633, 89/647, 94/7 and 92/121. 


\subsection{Results}

Table 5 provides a summary of the empirical results, and shows the regressions performed using both ordinary least squares and least square dummy variables or fixed effects. Furthermore, the estimation was carried out under the alternative hypothesis of random effects. The overall results are also shown for various independent variables, given the problems of specification mentioned above.

F-tests were run to check for fixed effects associated with the different periods considered in the sample, but it was decided not to include them (1). Furthermore, the regressions at the country level do not seem to indicate problems of autocorrelation. The random effects model is therefore taken into account only for a random effect associated with each cross-sectional unit. For this model the estimate of the proportion of total variance associated with this effect is very high, so the model resulting from estimation with generalised least squares should in principle be very similar to the model estimated with fixed effects (2).

Altogether the results provide an estimated value for the parameter $\beta_{1}$ of approximately -0.295 , and for $\beta_{2}$, the competition variable parameter, a positive value of 0.246 . Both parameters have the signs expected in the most suitable estimation, which seems to be the one including fixed country effects and the cumulative deregulation variable as a measurement of the level of competition. Parameter $\beta_{3}$ is negative in most specifications (between -0.01 and -0.03 ) and although it is not always statistically significant, it is, as expected, clearly lower in magnitude than parameter $\beta_{2}$. In summary, from the sample analysed we cannot rule out the hypothesis of competition on variable costs in the banking sector.

With regard to the magnitudes of the parameter estimates, the elasticities of concentration to changes in market size $\left(\eta_{S}\right)$ or the degree of competition $\left(\eta_{C}\right)$ can be obtained as follows:

$$
\begin{aligned}
& \eta_{\mathrm{S}}=\beta_{1}+\beta_{2} \mathrm{C}_{\mathrm{it}} \\
& \eta_{\mathrm{C}}=\left(\beta_{2}+\beta_{3} \ln \mathrm{S}_{\mathrm{it}}\right) \mathrm{C}_{\mathrm{it}}
\end{aligned}
$$

Using as parameter values $\beta_{1}=-0.295 ; \beta_{2}=0.246$ and $\beta_{3}=-0.012$, the evaluation of these elasticities at the sample means (see the descriptive statistics in Appendix 2) yields the following results:

$$
\eta_{\mathrm{S}}=-0.3416 \text { and } \eta_{\mathrm{C}}=0.3537
$$

The elasticity of concentration to changes in market size ranges in the sample between -0.295 and -0.403 . When evaluated at the sample means and keeping constant the level of competition, this elasticity implies that a $10 \%$ increase in market size (from total assets of 832,650 million US\$ to 915,915 million) results in a $3.4 \%$ decline in the concentration variable $\mathrm{CO}$. In terms of the more standard concentration variable $\mathrm{C} 5$, this implies a drop of 0.86 percentage points in the five-firm concentration ratio.

(1) The F-test for the inclusion of fixed effects for each country is 12.45 , with 14 and 139 degrees of freedom. This test therefore favours a specification including this type of effect. However, the F-test to check the possibility of adding time period effects has a value of 0.06 , with 10 and 153 degrees of freedom. This alternative is therefore clearly rejected.

(2) To estimate the random effects model we followed the method proposed by Judge et al. (1982), pp. 492-4. 
The elasticity of concentration to changes in competition ranges between 0.2522 for the market with the largest size and 0.477 for the smallest market. When evaluated at the sample means, and keeping the market size constant, an increase in competition of $10 \%$ (that is, from a value of the indicator of 3.88 to 4.28 ) leads to an increase in $\mathrm{CO}$ of $3.5 \%$, which in terms of the five-firm concentration ratio implies an increase of 0.86 percentage points.

Table 5. Regression results

\begin{tabular}{|c|c|c|c|c|c|c|c|c|}
\hline \multirow{2}{*}{$\begin{array}{l}\text { Regression method } \\
\text { Independent } \\
\text { variables }\end{array}$} & \multicolumn{2}{|c|}{ OLS } & \multicolumn{2}{|c|}{$\begin{array}{l}\text { Fixed effects } \\
\text { (country) }\end{array}$} & \multicolumn{2}{|c|}{$\begin{array}{c}\text { Fixed effects } \\
\text { (country and year) }\end{array}$} & \multicolumn{2}{|c|}{$\begin{array}{l}\text { Random effects } \\
\text { (country) }\end{array}$} \\
\hline & $\beta$ & $\mathrm{t}$ & $\beta$ & $\mathrm{t}$ & $\beta$ & $\mathrm{t}$ & $\beta$ & $t$ \\
\hline TA (real) & -0.270 & -5.094 & 0.211 & 2.504 & & & & \\
\hline CA & -0.059 & 0.072 & -0.051 & -0.119 & & & & \\
\hline Combined effect & 0.004 & 0.055 & 0.006 & 0.175 & & & & \\
\hline TA (real) & -0.268 & -3.687 & -0.295 & -4.649 & -0.466 & -1.918 & -0.152 & -1.426 \\
\hline $\mathrm{CC}$ & 0.391 & 1.892 & 0.246 & 1.990 & 0.266 & 2.319 & 0.216 & 1.890 \\
\hline Combined effect & -0.021 & -1.328 & -0.012 & -1.240 & -0.025 & -2.717 & -0.010 & -1.162 \\
\hline TA (nominal) & -0.274 & -3.811 & -0.087 & -0.951 & -0.459 & -1.883 & & \\
\hline $\mathrm{CC}$ & 0.389 & 1.907 & 0.173 & 1.474 & 0.252 & 2.211 & & \\
\hline Combined effect & -0.020 & -1.254 & -0.007 & -0.786 & -0.024 & -2.606 & & \\
\hline Revenue (real) & -0.339 & -5.803 & & & & & & \\
\hline & 0.260 & 0.33 & & & & & & \\
\hline Combined effect & -0.011 & -0.157 & & & & & & \\
\hline Revenue (real) & -0.267 & -3.304 & -0.019 & -0.212 & -0.112 & -0.861 & & \\
\hline $\mathrm{CC}$ & 0.453 & 2.383 & 0.350 & 3.168 & 0.344 & 3.104 & & \\
\hline Combined effect & -0.033 & -1.868 & -0.026 & -2.551 & -0.038 & -3.667 & & \\
\hline Revenue (nominal) & -0.271 & -3.362 & -0.005 & -0.061 & -0.11 & -0.84 & & \\
\hline $\mathrm{CC}$ & 0.457 & 2.392 & 0.315 & 2.807 & 0.334 & 3.017 & & \\
\hline Combined effect & -0.032 & -1.782 & -0.023 & -2.186 & -0.037 & -3.58 & & \\
\hline $\begin{array}{l}\text { TA: Total assets } \\
\text { CA: Deregulation } \\
\text { CC: Cumulative } \\
\text { deregulation }\end{array}$ & & & & & & & & \\
\hline
\end{tabular}

\section{Concluding remarks}

This paper discusses the impact of deregulation and market integration policies on the structure of European banking markets. The analysis focuses on the effect of market enlargement on concentration ratios, taking into account the competition effects of changes in the regulatory regime. 
The paper argues that the recent US literature on scale economies in banking highlights the existence of unexploited advantages associated with size, particularly when the effects of risk are taken into account. Following the theoretical distinction established by Sutton (1991) and Schmalensee (1992), this paper argues that whether European integration leads to an increased exploitation of scale advantages or not will depend on the extent to which competition in banking is based on fixed or variable costs. If competition focuses on variable costs, concentration will diminish with market enlargement, when we control for the pro-concentration effect triggered by the deregulation process.

Alternatively, if competition focuses on expenses unrelated to the level of intermediation, concentration will not tend to decline as the size of the market grows. This is due to the compensating effect of increased competition in fixed costs such as brand image or electronic banking. The paper also highlights the role of own funds as a source of endogenous increasing returns.

Finally, I propose a simple test using aggregate data that provides an empirical assessment of the dominant form of competition. The application of this procedure to data for eleven EU countries during the period 1981-1995 yields parameter estimates which indicate that over the period of analysis competition in Europe tends to be predominantly based on variable costs. On this basis, one would not expect large increases in European banking concentration as a result of market integration (EU14 concentration in 1995 was about 11\%, way below the figures for Japan $-22 \%$ - and the US -19\%-), and we would expect consolidation only at the level of some domestic markets.

The data set used in this paper does not allow a test of the extent to which the form of competition may have changed over time and further research should explore this possibility. Past competition may have been based on variable costs, but this could be a poor guide to future competitive conditions.

Moreover, the model focuses on retail activities, even though most large European deposit-taking institutions should be classified as universal banks. There is some uncertainty about the nature of competition in retail banking but little doubt that corporate and investment banking compete in a global market and are subject to substantial increasing returns. These structural features of wholesale and investment banking tend to foster global concentration.

To the extent that large European banks engage in wholesale banking, the key determinants of market structure in this industry may reinforce the trend towards fixed-cost competition between large commercial banks. This could result in a dichotomic European market structure where large pan-European banks coexist with geographically focused and specialized institutions.

This tendency could also be reinforced by the growing competition from non-bank institutions. Widening capital markets with the advent of the euro will facilitate entry and thus promote both the growth of the capital market activitities of universal banks and the appearance of smaller institutions specializing in capital market intermediation. 


\section{References}

Baldwin, R.E. and A. Venables (1995) "Regional Economic Integration" in G. Grossman and K. Rogoff (eds.) Handbook of International Economics, vol. III, North Holland.

Battarchaya, S. and A.V. Thakor (1993) "Contemporary Banking Theory" Journal of Financial Intermediation, vol. 3, 1, pp.2-50.

Barth, J.R., D.E., Nolle and T.N. Rice (1997) "Commercial Banking Structure, Regulation and Performance: An International Comparison" Economics Working Paper 97-6. Comptroller of the Currency. March.

Berger, A.N. and L.J. Mester (1997) "Inside the black box: What explains differences in the efficiencies of financial institutions" Journal of Banking and Finance, 21, pp. 895-947.

Berger, A.N., Hunter, W.C. and S.G. Timme (1993) "The efficiency of financial institutions: A review and preview of research past, present and future" Journal of Banking and Finance 17, 2-3, pp. 221-249.

Boot, A. and S. Greenbaum (1993) "Bank regulation, reputation and rents: Theory and policy implications" in Capital markets and financial intermediation, edited by C. Mayer and X. Vives. Cambridge: Cambridge University Press.

Cerasi, V. et al. (1998) "Sunk costs and the competitiveness of European banks after deregulation" Universitá degli Studi di Milano, Mimeo.

Davis, E.P. and S. Salo (1997) "Indicators of potential excess capacity in EU banking sectors", European Monetary Institute. Mimeo. November.

De Bandt, O. (1997) "EMU and the structure of the European banking system" European Monetary Institute. Mimeo. November.

Dell'Ariccia, G. (1998) "Asymmetric information and market structure of the banking industry" IMF Working Paper, June.

Demirgüç-Kunt, A. and H. Huizinga (1998) "Determinants of Commercial Bank Interest Margins and Profitability: some international evidence" Working Paper Series 1900, The World Bank, Washington.

Dermine, Jean (1986) "Deposit rates, credit rates and bank capital. The Klein-Monti model revisited" Journal of Banking and Finance 10, pp. 99-114.

Dewatripont, M. and J. Tirole (1994) The prudential regulation of banks, Cambridge, Mass.: MIT Press.

Economic Research Europe (1996) "A study of the effectiveness and impact of internal market integration on the banking and credit sector", report for the European Commission. The Single Market Review.

Freixas, X. and J.C. Rochet (1997) Microeconomics of banking, Cambridge, Mass.: MIT Press.

Gual, J. and D. Neven (1993) "Deregulation of the European banking industry" European Economy/Social Europe, no. 3, pp. 153-183

Hughes, J. and L.J. Mester (1998) "Bank capitalization and cost: evidence of scale economies in risk management and signaling" Review of Economics and Statistics, vol. 80, May, 2, pp. 314-325

Hughes, J.P., W. Lang, L.J. Mester and C.-G. Moon (1996) "Efficient Banking under Interstate Branching", Journal of Money, Credit and Banking vol. 28, 4, November, part 2, pp. 1045-1071.

Ito, T. and Y. Nagataki Sasaki (1998) "Impacts of the Basle Capital Standard on Japanese Banks' Behavior" NBER Working Paper 6730, September.

Klemperer, P. (1992) "Competition when consumers have switching costs: an overview" CEPR Discussion Paper 704.

Krasa, S. and A.P. Villamil (1992) "A Theory of Optimal Bank Size" Oxford Economic Papers 44, pp.725-749. 
McAllister, P.H. and D. Mc Manus (1993) "Resolving the scale efficiency puzzle in banking" Journal of Banking and Finance 17, 2-3, pp. 389-406.

Schmalensee, R. (1992) "Sunk costs and market structure: a review article" The Journal of Industrial Economics, vol.XL, 2, pp.125-134.

Sutton, J. (1991) Sunk costs and market structure: price competition, advertising and the evolution of concentration, Cambridge, Mass.: MIT Press.

Vives, X. (1991) "Banking competition and European integration" in European Financial Integration, edited by A. Giovannini and C. Mayer, CEPR/IMI. Cambridge: Cambridge University Press. 


\section{Appendix 1 \\ DEREGULATION, INTEGRATION AND MARKET STRUCTURE \\ IN EUROPEAN BANKING}

\section{Concentration, competition and market size}

Variable costs $(\alpha=0)$

The free-entry equilibrium relationship is given by:

$$
C R=\frac{1+\varepsilon}{\varepsilon+X}
$$

where $\mathrm{CR}=\left(1 / \mathrm{N}^{*}\right)$ and $\mathrm{X}=(\mathrm{gD} / \sigma)$

It is easy to check that:

$$
\frac{\partial C R}{\partial X}=\frac{(1+\varepsilon)}{(X+\varepsilon)^{2}}<0
$$

and

$$
\frac{\partial^{2} C R}{\partial X^{2}}=\frac{2(1+\varepsilon)}{(X+\varepsilon)^{3}}>0
$$

Similarly,

$$
\frac{\partial C R}{\partial \varepsilon}=\frac{(X-1)}{(X+\varepsilon)^{2}}>0
$$

Note that:

$$
\frac{\partial^{2} C R}{\partial X \partial \varepsilon}=\frac{\partial^{2} C R}{\partial \varepsilon \partial X}=\frac{(2+\varepsilon-X)}{(X+\varepsilon)^{3}}
$$

When $X>\varepsilon+2$ the cross partial will be negative. Otherwise, it will be zero or positive. Note, however, that the condition $X>\varepsilon+2$ is equivalent to $N^{*}=(X+\varepsilon) /(1+\varepsilon)>2$, which will be typically satisfied. 


\section{Appendix 1 (continued)}

\section{Fixed costs $(\alpha=1)$}

Using the same notation as before, the free-entry equilibrium is given by:

$$
C R(1-\varepsilon)+\varepsilon C R^{2}-\frac{1}{X}=0
$$

In this case:

$$
\frac{\partial C R}{\partial X}=\frac{-1 / X^{2}}{2 C R \varepsilon+(1-\varepsilon)}=<0
$$

since $2 \mathrm{CR} \varepsilon+(1-\varepsilon)>0$ given that $\mathrm{CR}$ is always larger than the lower bound $((\varepsilon-1) / \varepsilon)$.

Similarly,

$$
\frac{\partial C R}{\partial \varepsilon}=\frac{C R(1-C R)}{2 C R \varepsilon+(1-\varepsilon)}=>0
$$

With regard to the cross partial derivatives, we obtain the following expression:

$$
\frac{\partial^{2} C R}{\partial \varepsilon \partial X}=\frac{2 C R^{2} \varepsilon+(1-\varepsilon)(2 C R-1)}{(2 C R \varepsilon+(1-\varepsilon))^{3}}
$$

This expression will be larger than zero if $\varepsilon>1$ and $C R<(1 / 2)$ (or alternatively $N>2$ ). If $\varepsilon<1$, the expression could be negative if

$$
\varepsilon<\frac{1-2 C R}{1-2 C R+2 C R^{2}}
$$

This upper bound to $\varepsilon$ approaches unity as concentration diminishes. 
Appendix 2

DEREGULATION, INTEGRATION AND MARKET STRUCTURE

IN EUROPEAN BANKING

Summary statistics

\begin{tabular}{|l|r|r|r|r|}
\hline & & & & \\
Variable & Minimum & Maximum & \multicolumn{1}{c|}{ Mean } & Standard deviation \\
\hline C5 & 0.1931 & 0.9628 & 0.4977 & 0.1748 \\
lnCO & -1.43 & 3.25 & 0.0179 & 0.8343 \\
TA(real) & 28518.27 & 3817008 & 832650.1 & 870272.08 \\
ln(TA real) & 10.26 & 15.15 & 12.9392 & 1.3322 \\
CC & 0.00 & 9.00 & 3.8870 & 2.6538 \\
\hline N $=165$ & & & & \\
& & & & \\
\hline
\end{tabular}

C5: concentration variable, measured as the five-firm concentration ratio in terms of total assets TA(real): total assets in real terms (millions of US \$) CC: competition variable, measured as the cumulative deregulation indicator as described in the text. 